Vol 11, Issue 11, 2018

\title{
AMELIORATIVE EFFECT OF NARINGENIN AGAINST ANTITUBERCULOSIS DRUGS INDUCED ALTERATIONS IN HEMATOLOGICAL PARAMETERS OF RATS
}

\author{
NISHA SAHU ${ }^{1}$, GITA MISHRA ${ }^{1}$, HEMESHWER KUMAR CHANDRA ${ }^{1}$, SATENDRA KUMAR NIRALA ${ }^{2}$, \\ MONIKA BHADAURIA ${ }^{1 *}$
}

${ }^{1}$ Department of Zoology, Guru Ghasidas Vishwavidyalaya, Bilaspur - 495 009, Chhattisgarh, India. ${ }^{2}$ Department of Rural Technology and Social Development, Guru Ghasidas Vishwavidyalaya, Bilaspur - 495 009, Chhattisgarh, India. Email: bhadauria_monika@rediffmail.com

Received: 28 May 2018, Revised and Accepted: 09 July 2018

ABSTRACT

Objective: The aim of the present study was to evaluate the efficacy of naringenin against antituberculosis drugs (ATDs) induced alteration in hematological parameters in rats.

Methods: Rats were administered with ATDs for 8 weeks (3 days/weeks) followed by naringenin at three different doses (10, 20, and 40 mg/kg) conjointly for 8 weeks ( 3 days/weeks) orally. After 8 weeks, animals were euthanized; blood was collected by retro-orbital sinus method for the analysis of hematological parameters.

Results: The results of this study show decreased in red blood cells, hemoglobin, mean corpuscular volume, mean corpuscular hemoglobin, mean corpuscular hemoglobin concentration, platelets, and eosinophils along with increase in the number of lymphocytes in ATDs induced rats. Treatment with naringenin encountered ATDs induced hematological parameter alteration which was evident by significant reversal in hematological indices toward control in dose-dependent manner.

Conclusion: The present study concluded that ATDs exposure caused adverse effects in various blood components and conjoint treatment of naringenin reduced hematological alterations toward control due to antioxidant activity.

Keywords: Antituberculosis drugs, Naringenin, Hematological parameters, Rats.

(c) 2018 The Authors. Published by Innovare Academic Sciences Pvt Ltd. This is an open access article under the CC BY license (http://creativecommons. org/licenses/by/4. 0/) DOI: http://dx.doi.org/10.22159/ajpcr.2018.v11i11.27563

\section{INTRODUCTION}

Tuberculosis (TB) has been associated with significant morbidity and mortality and still remains a major global health problem. In 2015, the world had an estimated 10.4 million new TB cases in which over half of these were among men ( 5.9 million) and women constituted over a third (3.5 million), and $10 \%$ of cases were among children [1]. A multitherapy of the first-line antituberculosis drugs (ATDs) such as isoniazid, pyrazinamide, rifampicin, and ethambutol is used for the treatment of TB, for 2 months, followed by a combination of isoniazid/rifampicin for 8 months [2]. These ATDs can cause various minor and major adverse reactions in the body include skin reactions, gastrointestinal disorder, neurological disorder, and vertigo [3]. ATDs also cause alterations in liver function tests and cause severe hepatotoxicity $[4,5]$. Less scientific information is available on ATDs induced alterations in hematological parameter. Thus, the present study was undertaken to investigate the therapeutic potential of naringenin against ATDs induced alterations in hematological parameter.

Natural remedies from medicinal plants and natural products are considered to be effective and safe alternative treatment for blood-borne diseases. Naringenin is a plant bioflavonoid mainly found in grapefruit, tomato, and citrus fruit and considered to have beneficial effects on human health [6]. Naringenin is a polyphenolic compound containing two benzene rings connected together with a heterocyclic pyrone ring [7]. Naringenin possesses a plethora of biological and pharmacological effects. Naringenin reported as an antioxidant, antimicrobial, anticancer, cholesterol-lowering agent [8], antidepressant [9], anti-inflammatory [10], hepatoprotective, and nephroprotective agents [11,12]. Thus, it was hypothesized that naringenin may be helpful in ameliorates ATDs induced alteration in blood parameters in rats.

\section{MATERIALS AND METHODS}

Animals and chemicals

Female albino rats of Wistar strain $(150 \pm 10 \mathrm{~g}$ body weight $)$ housed under standard husbandry condition $\left(25 \pm 2^{\circ} \mathrm{C}\right.$ temp., $60-70 \%$ relative humidity, $14 \mathrm{~h}$ light, and $10 \mathrm{~h}$ dark) were used in the study. The animals were fed on standard pelleted diet and drinking water ad libitum. Experiments were conducted in accordance with the guidelines set by the Committee for the Purpose of Control and Supervision of Experiments on Animals (CPCSEA), India. The study was carried out with the approval of the institutional animal ethics committee (994/Ere/Go/06/CPCSEA). The ATDs such as isoniazid, rifampicin, ethambutol, and pyrazinamide were generously obtained from the Government TB Hospital, Bilaspur (C.G.). Naringenin was purchased from Sigma-Aldrich Company.

\section{Experimental protocols}

Animals were divided into various groups of six animals each. Group I served as control and received vehicle only. Group II was administered with naringenin per se at the dose of $40 \mathrm{mg} / \mathrm{kg}$ orally. Groups III-VII were administered with pyrazinamide, ethambutol, isoniazid, and rifampicin at the doses of $210,170,85$, and $65 \mathrm{mg} / \mathrm{kg}$, respectively, for 8 weeks ( 3 alternative days in a week) and Group III served as experimental control. Animals of Groups IV, V, and VI were given naringenin at the doses of 10,20 , and $40 \mathrm{mg} / \mathrm{kg}$, p.o, respectively, for 8 weeks ( 3 alternative days in a week considering every next day of ATDs exposure). Group VII was treated with silymarin at dose of $50 \mathrm{mg} / \mathrm{kg}$, p.o, same as naringenin as positive control. After $24 \mathrm{~h}$ of last treatment, blood was drawn from retro-orbital venous sinus by the conventional method [13]. Blood samples collected in ethylenediaminetetraacetic acid anticoagulant tubes (8.5\%) were quickly returned by mixing with anticoagulant in the tube. Hematological parameters were analyzed: 
Red blood cells (RBC), hemoglobin, mean corpuscular volume (MCV), mean corpuscular hemoglobin (MCH), mean corpuscular hemoglobin concentration $(\mathrm{MCHC})$, platelets, eosinophils, and the number of lymphocytes (LYM). All hematological parameters were analyzed using the automated method with the automatic analyzer "Hematology Autoanalyzer Hema 2062+."

\section{Statistical analysis}

The results were expressed as mean \pm standard error of six animals used in each group. The differences between mean values were calculated by one-way analysis of variance (ANOVA) considered statistically significant at $\mathrm{p} \leq 0.05$ level followed by student's t-test [14].

\section{RESULTS AND DISCUSSION}

Hematological studies are useful in the diagnosis of the root cause of many diseases [15]. Hematological disorders indicate the abnormal condition in the profile of blood parameters, due to changes in metabolism. Long-term exposure to ATDs medication increases the risk of adverse drug reactions and toxicity. Isoniazid and rifampicin may directly cause hemolytic anemia [16]. The mean and standard deviation of hematological parameters such as RBC, hemoglobin, mean corpuscular volume, $\mathrm{MCH}$, and $\mathrm{MCHC}$ of the blood of rats exposed to ATDs, and therapeutic effect of different doses of naringenin is shown in Table 1. Previous findings showed that administration of ATDs for 30 days altered the blood parameters results in decrease in $\mathrm{RBC}$ and hemoglobin in rats [17]. In the present study, rats treated with ATDs for 8 weeks showed decrease in RBC compared to control which, in turn, indicates anemic condition. Hemoglobin decreased significantly $(\mathrm{p} \leq 0.05)$ in the blood of ATDs induced rats relative to the control. However, reduction in hemoglobin can be probably due to the production of reactive oxygen species formed by the toxic metabolites of ATDs at the time of biotransformation of drugs. This results in the destruction of the RBC membrane and its function. MCV is a measure of the average volume of an RBC. A low MCV is an indication of microcytic anemia. The result suggests that the ATDs treated groups may have anemia as MCV is significantly lower $(p \leq 0.01)$ as compared to control groups increase the anemic condition in rats. $\mathrm{MCH}$ and $\mathrm{MCHC}$ are major indices for evaluating circulatory erythrocytes and used in the diagnosis of anemia and also serve as useful indices of the bone marrow capacity to produce RBCs as in mammals [18]. The $\mathrm{MCH}$ and MCHC were seen to be decreased in ATDs exposed groups might be due to decreased production of hemoglobin.

All the three doses of naringenin maintained RBC, hemoglobin, mean corpuscular volume, $\mathrm{MCH}$, and MCHC near to control. Mean values depicted that naringenin doses of 10,20 , and $40 \mathrm{mg} / \mathrm{kg}$ therapy maintain hematological variables toward control, but $40 \mathrm{mg} / \mathrm{kg}$ dose of naringenin showed significantly $(\mathrm{p} \leq 0.01)$ increase in hemoglobin level. This increase may arise as a result of increase RBC count and possibly the mineral content of naringenin, especially iron content, an increase in iron supply is necessary to elevate the hemoglobin content. This suggests that naringenin may be useful in anemic conditions. Naringenin could modulate the heme metabolism and was noted for its biosynthetic ability under physiological and toxicological conditions, thereby minimizes the toxic effects in the blood. 20 and $40 \mathrm{mg} / \mathrm{kg}$ doses of naringenin show significant restoration in MCV ( $\mathrm{p} \leq 0.01)$. Naringenin has ability to restore the MCV, MCH, and $\mathrm{MCHC}$ toward control and reduce the anemic condition in rats. The results were well compared with silymarin-treated positive control.

The therapeutic effect of naringenin on blood parameter such as platelets, eosinophils, and LYM against ATDs induced toxicity is well presented in Table 2. Blood platelets are implicated in blood clotting. ATDs administered rats showed low platelet concentration suggests that the process of clot formation resulting in excessive loss of blood in case of injury. Eosinophils are a type of white blood cell formed in the bone marrow. Prolonged use of ATDs caused alteration in eosinophil level $[19,20]$. Present findings showed significant $(p \leq 0.01)$ decrease in the eosinophils count. The main role of LYM is to fight infections. Increased level of LYM showed that rats are more prone to have disease. The present observation indicates that ATDs groups have low immune system as they have elevated level of LYM in comparison to control groups ( $\mathrm{p} \leq 0.01)$.

In the present study, naringenin therapies 10,20 , and $40 \mathrm{mg} / \mathrm{kg}$ doses show protective effect by normalizing the levels of treated

Table 1: Therapeutic effect of naringenin on blood parameter against ATDs induced toxicity

\begin{tabular}{|c|c|c|c|c|c|}
\hline Groups & $\operatorname{RBC}\left(10^{6} / \mathrm{mm}^{3}\right)$ & $H b(g / d L)$ & $\operatorname{MCV}(\mathrm{fl})$ & MCH (pg) & MCHC (g/dL) \\
\hline Control & $7.26 \pm 0.41$ & $15.2 \pm 0.91$ & $50.7 \pm 3.93$ & $19.7 \pm 1.68$ & $41.3 \pm 3.31$ \\
\hline Naringenin per se & $7.16 \pm 0.44$ & $15.3 \pm 0.90$ & $51.9 \pm 4.05$ & $19.9 \pm 1.72$ & $42.1 \pm 3.33$ \\
\hline ATD & $6.35 \pm 0.43$ & $12.1 \pm 0.69^{\psi}$ & $33.1 \pm 2.70^{\phi}$ & $16.5 \pm 1.02$ & $33.6 \pm 2.88$ \\
\hline ATD+Nar 10 & $6.69 \pm 0.47$ & $12.8 \pm 0.94$ & $42.2 \pm 3.96$ & $18.1 \pm 1.82$ & $38.8 \pm 2.43$ \\
\hline ATD+Nar 20 & $6.82 \pm 0.39$ & $13.7 \pm 0.84$ & $47.6 \pm 3.75 * *$ & $18.4 \pm 1.88$ & $39.0 \pm 2.31$ \\
\hline ATD+Nar 40 & $7.26 \pm 0.41$ & $14.9 \pm 0.84 *$ & $48.8 \pm 3.81 * *$ & $18.7 \pm 1.75$ & $40.1 \pm 3.26$ \\
\hline ATD+Sily 50 & $7.16 \pm 0.44$ & $14.8 \pm 0.96 *$ & $50.9 \pm 4.01 * *$ & $19.2 \pm 1.71$ & $40.9 \pm 3.28$ \\
\hline
\end{tabular}

Data are mean \pm SE of $n=6 ;{ }^{\psi}$ ATD versus control at $p \leq 0.05,{ }^{\phi}$ ATD versus control at $p \leq 0.01, *$ ATD+Therapy versus ATD at $p \leq 0.05, * *$ ATD+Therapy versus ATD at $p \leq 0.01$, ${ }^{\S}$ Significant at 5\% for ANOVA: Analysis of variance. RBC: Red blood cells, Hb: Hemoglobin, HCT: Hematocrit, MCV: Mean corpuscular volume, MCH: Mean corpuscular hemoglobin, MCHC: Mean corpuscular hemoglobin concentration, ATDs: Antituberculosis drugs, Nar 10: Naringenin $10 \mathrm{mg} / \mathrm{kg}$, Nar 20: Naringenin 20 mg/kg, Nar 40: Naringenin 40 mg/kg, Sily 50: Silymarin 50 mg/kg, SE: Standard error

Table 2: Therapeutic effect of naringenin on blood parameter against ATDs induced toxicity

\begin{tabular}{llll}
\hline Groups & Platelets $\left(\mathbf{1 0}^{\mathbf{6}} / \mathbf{m m}^{\mathbf{3}}\right)$ & Eosinophils $\left(\mathbf{1 0} \mathbf{6} \mathbf{m m}^{\mathbf{3}}\right)$ & $\mathbf{L Y M}\left(\mathbf{1 0 ^ { 3 }} / \mathbf{m m}^{\mathbf{3}}\right)$ \\
\hline Control & $850 \pm 71.7$ & $4.4 \pm 0.32$ & $72.5 \pm 4.33$ \\
Naringenin per se & $803 \pm 78.1$ & $4.5 \pm 0.31$ & $73.2 \pm 4.19$ \\
ATD & $695 \pm 56.4$ & $1.2 \pm 0.07$ & $92.0 \pm 5.12^{\psi}$ \\
ATD+Nar 10 & $711 \pm 62.0$ & $3.5 \pm 0.29 * *$ & $90.0 \pm 4.96$ \\
ATD+Nar 20 & $734 \pm 59.7$ & $3.5 \pm 0.29 * *$ & $88.2 \pm 5.28$ \\
ATD+Nar 40 & $794 \pm 60.7$ & $4.2 \pm 0.34 * *$ & $84.0 \pm 4.81$ \\
ATD+Sily 50 & $825 \pm 60.3$ & $4.3 \pm 0.33 * *$ & $80.6 \pm 4.10$ \\
ANOVA & 1.02 & $18.7^{\S}$ & $3.34^{\S}$ \\
\hline
\end{tabular}

Data are mean \pm SE of $n=6 ;{ }^{\psi}$ ATD versus control at $\mathrm{p} \leq 0.05,{ }^{\phi}$ ATD versus control at $p \leq 0.01, * A T D+T h e r a p y$ versus ATD at $p \leq 0.05, * * A T D+$ Therapy versus ATD at $p \leq 0.01$,

§Significant at 5\% for ANOVA: Analysis of variance. RDW: Red cell distribution width, LYM: Lymphocytes; ATDs: Antituberculosis drugs, Nar 10: Naringenin 10 mg/kg,

Nar 20: Naringenin 20 mg/kg, Nar 40: Naringenin 40 mg/kg, Sily 50: Silymarin 50 mg/kg, SE: Standard error 
blood parameters. Naringenin capable to increase the platelet count as previously reported that they have wound healing properties [21]. Naringenin significantly $(\mathrm{p} \leq 0.01)$ maintained eosinophil level near control in dose-dependent manner. Treatment of naringenin also decreases LYM and improved body's defense mechanism. No adverse effect was found in the blood parameters after per se treatment of naringenin. Naringenin showed dose-dependent recovery, especially $40 \mathrm{mg} / \mathrm{kg}$ significantly elevate the RBC, hemoglobin, mean corpuscular volume, MCH, MCHC, platelets, and eosinophils along with decrease in the number of LYM to normalcy indicating capability of naringenin to scavenge free radicals caused by reactive metabolites of ATDs.

\section{CONCLUSION}

Administration of ATDs for 8 weeks caused changes in hematological parameters in rats. It can be concluded that naringenin has potential to reverse ATDs induced blood parameters alterations thus can be used as an excellent protective agent during ATDs regimen.

\section{ACKNOWLEDGMENT}

The authors are thankful to Chhattisgarh Institute of Medical Science, Bilaspur, for ATDs, Guru Ghasidas Vishwavidyalaya, for providing laboratory facilities.

\section{AUTHOR'S CONTRIBUTION}

All the authors have contributed equally.

\section{CONFLICTS OF INTEREST}

The authors declare that they have no conflicts of interest.

\section{REFERENCES}

1. World Health Organization. Global Tuberculosis Report; 2017.

2. Tostmann A, Boeree MJ, Aarnoutse RE, de Lange WC, van der Ven AJ, Dekhuijzen R, et al. Antituberculosis drug-induced hepatotoxicity: Concise up-to-date review. J Gastroenterol Hepatol 2008;23:192-202.

3. Arbex MA, Varella Mde C, Siqueira HR, Mello FA. Antituberculosis drugs: Drug interactions, adverse effects, and use in special situations. Part 2: Second line drugs. J Bras Pneumol 2010;36:641-56.

4. Chrestella JM, Ginting MA, Dalimunthe A, Nasuton R. Hepatoprotective activity combination of Curanga fel-terrae lour leaves and Curcuma heyneana valeton and Zijprhizhome in rat induced by combination of rifampicin and isoniazid. Int J Pharm Pharm Sci 2017;9:23-8.
5. Buntoro IF, Sumardi KE. Decrease of liver function after treatment of antituberculosis drugs in tuberculosis patients with malnutrition and alcohol consumption. Int J Pharm Pharm Sci 2016;8:269-37.

6. Kapoor R, Kakkar P. Naringenin accords hepatoprotection from streptozotocin induced diabetes in vivo by modulating mitochondrial dysfunction and apoptotic signaling cascade. Toxicol Rep 2014;1:569- 81

7. Tripoli E, La Guardia M, Giammanco S, Di Majo D, Giammanco M. Citrus flavonoids: Molecular structure, biological activity and nutritional properties: A review. Food Chem 2007;104:466-79.

8. Jeon SM, Bok SH, Jang MK, Kim YH, Nam KT, Jeong TS, et al. Comparison of antioxidant effects of Naringin and probucol in cholesterol-fed rabbits. Clin Chim Acta 2002;317:181-90.

9. Yi LT, Li J, Li HC, Su DX, Quan XB, He XC, Wang XH. Antidepressant-like behavioral, neurochemical and neuroendocrine effects of naringenin in the mouse repeated tail suspension test. Prog Neuro Psycho Pharmacol Biol Psychiatry 2012;39(1):175-81.

10. Yoshida H, Watanabe W, Oomagari H, Tsuruta E, Shida M, Kurokawa $\mathrm{M}$, et al. Citrus flavonoid Naringenin inhibits TLR2 expression in adipocytes. J Nutr Biochem 2013;24:1276-84.

11. Renugadevi J, Prabu SM. Cadmium-induced hepatotoxicity in rats and the protective effect of Naringenin. Exp Toxicol Pathol 2010;62:171- 81.

12. Renugadevi J, Prabu SM. Naringenin protects against cadmium-induced oxidative renal dysfunction in rats. Toxicology 2009;256:128-34

13. Riley V. Adaptation of orbital bleeding technic to rapid serial blood studies. Proc Soc Exp Biol Med 1960;104:751-4.

14. Gupta SC. Fundamentals of Statistics. $7^{\text {th }}$ ed. New Delhi: Himalaya Publishing House; 2012. p. 19.1-36.

15. Etim NN, Williams ME, Akpabio U, Offiong EE. Haematological parameters and factors affecting their values. J Agric Sci 2014;2:37-7.

16. Kassa E, Enawgaw B, Gelaw A, Gelaw B. Effect of anti-tuberculosis drugs on hematological profiles of tuberculosis patients attending at university of gondar hospital, northwest ethiopia. BMC Hematol 2016;16:1

17. Bharti U, Kumar NR, Kaur J. Ameliorating effect of bee pollen against anti-tuberculosis drugs (Rifampicin and Isoniazid) induced toxicity on hematology of Sprague dawley rats. Asian J Pharm Clin Res 2017; 10:188-90

18. Chineke CA, Ologun AG, Ikeobi CO. Haematological parameters in rabbit breeds and crosses in humid tropics. Pak J Biol Sci 2006;9:2102- 6.

19. Wong PC, Yew WW, Wong CF, Choi HY, Ethambutol-induced pulmonary infiltrates with eosinophilia and skin involvement. Eur Respir J 1995;8:866-68.

20. Lange P, Oun H, Fuller S, Turney JH. Eosinophilic colitis due to rifampicin (letter). Lancet 1994;344:1296-7.

21. Al-Roujayee AS. Naringenin improves the healing process of thermallyinduced skin damage in rats. J Int Med Res 2017;45:570-82. 